\title{
Estudo da inibição de HMF e furfural na fermentação do hidrolisado de madeira de Eucalyptus urophylla
}

\author{
S. T. ALVES ${ }^{1}$, T. F. PACHECO ${ }^{2}$, C. M. M. MACHADO ${ }^{2}$, BRENNO. A. D. NETO ${ }^{1}$ e S. B. \\ GONÇALVES ${ }^{2}$ \\ ${ }^{1}$ Universidade de Brasília, Instituto de Química \\ ${ }^{2}$ Empresa Brasileira Pesquisa Agropecuária - Agroenergia, Laboratório de Processos Bioquímicos \\ E-mail para contato: suteixeira76@yahoo.com.br
}

\begin{abstract}
RESUMO - Os resíduos de madeira têm se mostrado promissores para a produção de etanol lignocelulósico. Observa-se que há uma gama de estudos enfocando as etapas de pré-tratamento e hidrólise enzimática nesta área, contudo não se observa a mesma preocupação com a fermentação. Neste trabalho foi avaliada a fermentação do hidrolisado de Eucalyptus urophylla, obtido através de pré-tratamento físico-químico e hidrólise enzimática (Cellic ${ }^{\circledR}$ CTec2). As fermentações foram realizadas utilizando a levedura (Saccharomyces cerevisiae) CAT-1. Os resultados mostraram que para o meio sintético (YPG) obteve-se a eficiência máxima para a produção de etanol, contudo para o hidrolisado a eficiência foi de aproximadamente $84 \%$ e para o meio sintético com quantidades de HMF e furfural de $7 \times 10^{-3} \mathrm{~g} / \mathrm{L}$ e $2,6 \times 10^{-2} \mathrm{~g} / \mathrm{L}$ respectivamente, foi de 91,6\%. Demonstrou-se que estes inibidores reduzem a eficiência, mas que não são os únicos responsáveis pela baixa eficiência na fermentação do hidrolisado.
\end{abstract}

\section{INTRODUÇÃO}

A produção de etanol lignocelulósico é considerada um marco para o desenvolvimento sustentável. Embora a produção de etanol a partir da cana-de-açúcar e do amido de milho sejam tecnologias bem desenvolvidas, a biomassa lignocelulósica, como resíduos agrícolas, resíduos florestais e resíduos sólidos urbanos, representa uma fonte em potencial de matéria-prima para a produção de etanol, uma vez que é uma matéria-prima barata, abundante e sustentável, que está disponível em todo o mundo e ocorre como um subproduto, sem usos competitivos (Yanase et al., 2012).

Um dos entraves do uso destes materiais é a necessidade de um pré-tratamento que disponibilize a celulose para que a hidrólise enzimática seja efetiva. Isso se dá pela rigidez estrutural conferida pela lignina, grau de acetilação da hemicelulose e o próprio grau de polimerização e cristalinidade da celulose, que atuam como bloqueio, impedindo o acesso das enzimas celulases (Sun e Cheng, 2002).

No entanto, estes pré-tratamentos além de formarem açúcares derivados da hidrólise e da 


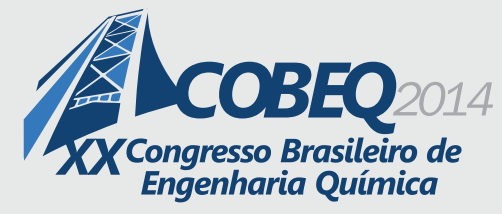

19 a 22 de outubro de 2014

Florianópolis/SC

degradação da celulose e hemicelulose, formam, também, compostos que podem atuar como inibidores na fermentação. A natureza e concentração destes compostos dependem do tipo de biomassa pré-tratada, assim como das condições do processo (Caetano e Madaleno, 2011). Estes produtos de degradação, que são potenciais inibidores da fermentação, se agrupam em três classes: os derivados do furano; ácidos alifáticos de baixa massa molecular; e derivados fenólicos (Moon e Liu, 2012). Em função das elevadas temperaturas aplicadas nos pré-tratamentos, os açúcares produzidos na hidrólise, principalmente da hemicelulose, se degradam gerando os compostos derivados do furano: o furfural, formado a partir da degradação das pentoses (xilose e arabinose) e o 5-hidroximetilfurfural (HMF), formado como consequência da degradação das hexoses (glicose, manose e galactose) (Moon e Liu, 2012). Estes compostos derivados do furano se comportam como inibidores dos microrganismos, danificando as paredes e membranas celulares, inibindo o crescimento celular, reduzindo as atividades enzimáticas e consequentemente a produção de etanol (Olea et al., 2012). O presente trabalho tem como objetivo avaliar a inibição da levedura em função da presença de inibidores HMF e furfural, formados/provenientes da etapa de prétratamento.

\section{MATERIAIS E MÉTODOS}

\subsection{Material}

Para a produção dos hidrolisados lignocelulósicos foi utilizada a espécie de eucalipto Eucalyptus urophylla. $\mathrm{Na}$ hidrólise enzimática utilizou-se o complexo enzimático Cellic ${ } \mathrm{CTec} 2$, da Novozymes. A fermentação alcóolica foi realizada utilizando-se a levedura CAT-1.

\subsection{Métodos}

Preparo da biomassa: O material lignocelulósico que se encontrava em forma de cavacos foi processado em moinho de facas tipo Willey, modelo Macor Star FT-60, da marca Fortinox., até granulometria máxima de $3 \mathrm{~mm}$.

Pré-tratamento: O material seco e moído foi pré-tratado adicionando-se ácido sulfúrico 1,5\% (v/v) à biomassa, numa razão sólido/líquido de 1/10. Esta suspensão foi mantida por 30 minutos em autoclave a $121{ }^{\circ} \mathrm{C}$. Este material foi filtrado e o sólido lavado com água. Ao sólido lavado, adicionou-se hidróxido se sódio $4 \%(\mathrm{~m} / \mathrm{v})$, na razão sólido/líquido de 1/10. Esta suspensão foi autoclavada por 30 minutos a $121{ }^{\circ} \mathrm{C}$. Este material foi filtrado e o sólido retirado deste prétratamento lavado com água fervente. Parte da fração sólida de ambas as etapas foi reservada para a determinação de umidade do material em estufa de secagem a $105^{\circ} \mathrm{C}$ e caracterização quanto ao teor de celulose e hemicelulose.

Caracterização da biomassa: O material bruto e frações sólidas obtidas nos pré-tratamentos ácido e alcalino (após secagem) passaram por caracterização química para determinar o teor de celulose e hemicelulose, segundo metodologia de hidrólise ácida adaptada de Gouveia et al., 2009. As amostras foram diluídas e clarificadas em cartuchos $\mathrm{C} 18$ e em seguida analisadas utilizando coluna Aminex HPX $87 \mathrm{H}$ e detector de índice de refração no cromatógrafo líquido de alta 


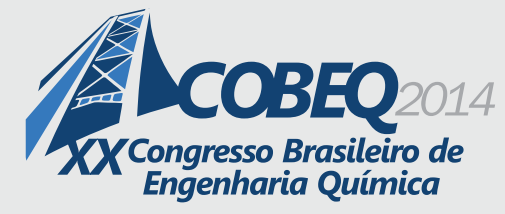

eficiência - CLAE, modelo 1260 Infinity, da marca Agilent Technology.

Hidrólise enzimática: $\mathrm{O}$ material pré-tratado foi submetido à hidrólise enzimática empregando 15 FPU do extrato enzimático comercial Cellic ${ }^{\circledR}$ CTec2 2 por grama de substrato seco em tampão citrato de sódio/ácido cítrico $0,1 \mathrm{~mol} / \mathrm{L}$ e pH 5,0 numa razão sólido/líquido de 1/10. A hidrólise foi realizada em Shaker orbital de bancada com incubação e refrigeração, modelo Max 4000, da marca Thermo Scientific, a $50{ }^{\circ} \mathrm{C}$ e $200 \mathrm{rpm}$ por 24 horas.

Fermentação: Meio sintético: Foi utilizado o meio de cultura YPG, nas concentrações de 1, 0,5 e $10 \%$ para extrato de levedura, peptona bacteriologia e glicose respectivamente. Para o isolamento da colônia de levedura fez-se o plaqueamento com meio sólido YPG $2 \%$. O meio de cultura e todo o material usado na fermentação foram autoclavados por 30 minutos a $121{ }^{\circ} \mathrm{C}$. Com a técnica de plaqueamento a levedura foi isolada em colônias. Colônias isoladas de $S$. cerevisiae (CAT-1) foram inoculadas em meio rico e mantidas em shaker a $30^{\circ} \mathrm{C}$ e $150 \mathrm{rpm}$ para propagação por 12 horas. A fermentação em meio sintético e o crescimento da levedura foram realizados em Shaker a $30{ }^{\circ} \mathrm{C}$ e $150 \mathrm{rpm}$, com inoculo de $10 \%$. Meio hidrolisado: Após análise para obtenção da concentração de glicose presente no hidrolisado, adicionou-se glicose até que a concentração final do meio alcançasse $100 \mathrm{~g} / \mathrm{L}$. O meio hidrolisado foi inoculado com $10 \mathrm{~g} / \mathrm{L}$ de levedura (CAT-1) crescida anteriormente no meio sintético e a fermentação ocorreu conforme descrito anteriormente. Meio sintético com inibidores: Com as concentrações dos inibidores furfural e HMF encontradas no hidrolisado, adicionou-se, em quantidades equivalentes, as substâncias ao meio sintético e verificou-se o comportamento da levedura. A fermentação ocorreu de forma semelhante às anteriores.

Análises: Após as etapas de pré-tratamento e da hidrólise enzimática foram feitas análises, em cromatografia líquida de alta eficiência (CLAE), para a quantificação de inibidores e açúcares, bem como as alíquotas retiradas em cada etapa dos processos de hidrólise enzimática e de fermentação também foram analisadas pela mesma técnica. A concentração de células foi determinada através de leitura da densidade ótica em espectrofotômetro multimodal com absorbância UV/VIS, modelo Spectramax, da marca Molecular Devices, a $650 \mathrm{~nm}$ utilizando-se uma relação pré-estabelecida entre a concentração de células e a absorbância.

Cálculos dos parâmetros de fermentação: Os parâmetros cinéticos da fermentação foram obtidos através da utilização dos cálculos da taxa específica máxima de crescimento, dos fatores de conversão de substrato em células e em produto e da eficiência de fermentação.

Taxa específica máxima de crescimento $\left(\mu_{\max }\right)$ : A taxa específica de crescimento celular $(\mu)$ foi calculada pela Equação 1.

$$
\mu=\frac{1}{X} \cdot \frac{d X}{d t}
$$

Onde X é a concentração celular (g/L) e t é o tempo (minutos). 
Fator de conversão de substrato em produto (Y $\mathrm{Y} / \mathrm{S})$ : $\mathrm{O}$ fator de conversão de substrato em produto foi expresso em $\mathrm{g}_{\text {etanol }} / \mathrm{g}_{\text {glicose }}$, sendo calculado através da Equação 2.

$$
Y_{P / S}=\frac{d P}{-d S}
$$

Onde P é a concentração do produto (g/L) e $\mathrm{S}$ é a concentração de substrato (g/L).

Fator de conversão de substrato em células $\left(\mathrm{Y}_{\mathrm{X} / \mathrm{S}}\right)$ : $\mathrm{O}$ fator de conversão de substrato em células foi expresso em $\mathrm{g}_{\text {células }} / \mathrm{g}_{\mathrm{glicose}}$, sendo calculado através da Equação 3.

$$
Y_{X / S}=\frac{d X}{-d S}
$$

Eficiência de fermentação (E): Foi calculada com base no rendimento teórico proveniente da equação de Gay-Lussac (51,1 $\mathrm{g}_{\text {etanol }} / 100 \mathrm{~g}_{\text {glicose }}$ ) (Ilha et al., 2008), segundo a Equação 4.

$$
E=Y_{P / S} .100 / 0,511
$$

\section{RESULTADOS E DISCUSSÃO}

Caracterização química do material bruto e pré-tratado: os resultados da caracterização química da madeira em seu estado natural (bruta) e depois de passar pelas etapas de prétratamento ácido e do ácido seguido do alcalino são discutidos para a quantidade de celulose e hemicelulose disponibilizada após a etapa de pré-tratamento.

Na caracterização do eucalipto da espécie Eucalyptus urophylla, a quantidade de celulose verificada, dada pela média das análises realizadas, foi de $28 \%$. Este valor não é compatível ao encontrado na literatura, na qual, para a mesma espécie, está na faixa de 35 a $50 \%$ (Gomide et al., 2010). Para a hemicelulose, o valor encontrado foi de $8 \%$ e na literatura o valor está na faixa de 17 a 19\%. Esta diferença ocorre, possivelmente, pela diferença no método utilizado na caracterização e nas variáveis como concentração do ácido sulfúrico e temperatura (Mokfienski e Gomide, 2003). Após o pré-tratamento ácido, o percentual de celulose disponibilizada foi de $32 \%$ e da hemicelulose $6 \%$. Na etapa seguinte, alcalina, o percentual de celulose foi de $40 \%$ e a de hemicelulose de $2 \%$.

Hidrólise enzimática: nesta etapa os resultados são restritos aos pontos inicial e final, uma vez que este estudo tem como foco principal o processo de fermentação. Por meio da curva padrão obtida no CLAE, pôde-se quantificar a glicose formada durante o processo. Obteve-se, com 24 horas de hidrólise enzimática, 20,7 g/L de glicose no meio. De acordo com a metodologia de 


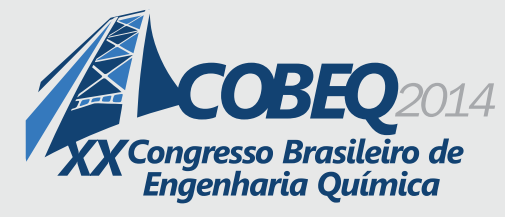

caracterização, o rendimento máximo esperado seria de 40,0 g/L, com isso foi observado que o rendimento médio da hidrólise foi de $59 \%$ com o pré-tratamento aplicado. Esta conversão já era esperada visto que a madeira é um material muito recalcitrante quando comparado com outras biomassas. Soma-se a isso o fato de que a proporção sólido/líquido em todas as etapas dos processos é 1:10, o que normalmente não é encontrado na literatura, que, em geral, é de 1:30 (referências). Esta proporção foi utilizada visando-se um processo em escala industrial.

Fermentação: As fermentações foram conduzidas seguindo o procedimento descrito na metodologia e apresentaram resultados muito diferentes. $\mathrm{O}$ comportamento quanto ao crescimento da levedura no meio sintético foi o esperado, já que é um meio rico e contém todos os nutrientes necessários para o seu desenvolvimento. $\mathrm{O}$ resultado do meio sintético foi usado como meio de comparação com os outros dois meios analisados, como mostra a Figura 1.



(A)

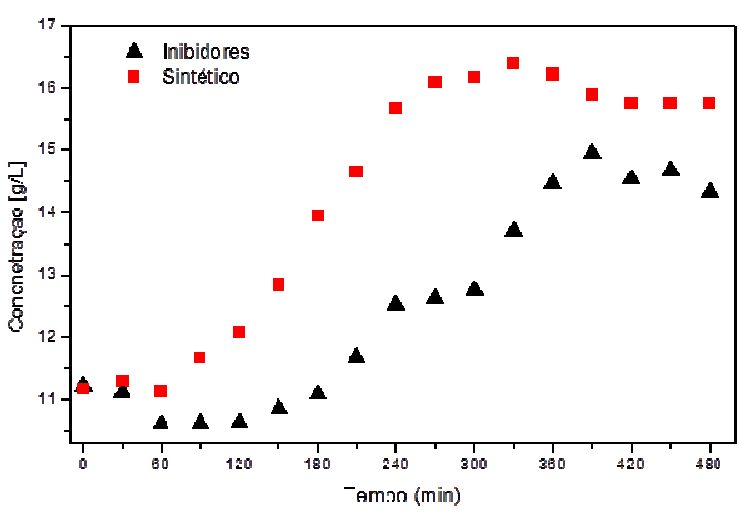

(B)

Figura 1 - Crescimento da levedura: (A) Comparação do meio sintético com o meio hidrolisado; (B) Comparação do meio sintético com o meio sintético com inibidores.

No meio sintético a fase Lag pode ser considerada curta, o que indica uma rápida adaptação dos microrganismos ao meio. Já no meio hidrolisado observa-se a não adaptação e um crescimento muito lento da levedura, Figura 1 (A). Isso fica evidente ao se comparar os fatores de conversão de substratos em células $\left(\mathrm{Y}_{\mathrm{X} / \mathrm{S}}\right)$ nos dois meios. No meio sintético a levedura apresentou o fator de conversão de $0,051 \mathrm{~g}_{\text {célula }} / \mathrm{g}_{\text {glicose }}$ com um desvio padrão médio de $\pm 0,005$ e no meio hidrolisado apresentou $0,023 \mathrm{~g}_{\text {célula }} / \mathrm{g}_{\text {glicose }}$ com desvio padrão de $\pm 0,003$, em valores absolutos podemos afirmar que o fator de convenção no meio hidrolisado é quase metade do meio sintético, mostrando realmente que a levedura não se adaptou ao meio hidrolisado. Diante destes resultados foi analisada a presença dos inibidores furfural e HMF no hidrolisado, e encontrou-se concentrações de $0,026 \mathrm{~g} / \mathrm{L}$ para o furfural e $0,007 \mathrm{~g} / \mathrm{L}$ para o HMF. De posse destas concentrações, estes compostos foram adicionados ao meio sintético e verificou-se que a levedura não se desenvolveu como no meio sintético sem inibidores, conforme mostra a Figura 1 (B). Ao compararmos os fatores de conversão do meio sintético $\left(\mathrm{Y}_{\mathrm{X} / \mathrm{S}}=0,051 \mathrm{~g}_{\text {célula }} / \mathrm{g}_{\mathrm{glicose}}\right)$ e do meio 


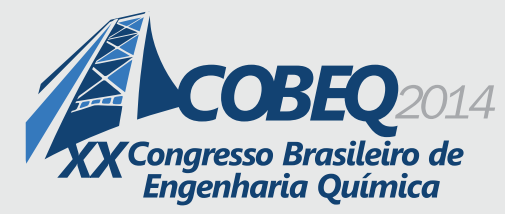

hidrolisado $\left(\mathrm{Y}_{\mathrm{X} / \mathrm{S}}=0,023 \mathrm{~g}_{\text {célula }} / \mathrm{g}_{\mathrm{glicose}}\right)$ com o meio contendo inibidores, $\mathrm{Y}_{\mathrm{X} / \mathrm{S}}=0,033 \pm 0,007$ $\mathrm{g}_{\text {célula }} / \mathrm{g}_{\text {glicose, }}$ verificou-se que o aumento na concentração de células no meio sintético com a presença de inibidores foi de $28 \%$, e se compararmos com o meio sintético puro que foi de $41 \%$ e com o meio hidrolisado que foi de $17 \%$ constatamos que houve uma queda em relação ao meio padrão, mas um aumento em relação ao meio hidrolisado.

O fato de a levedura ter se desenvolvido, mesmo que precariamente, na presença de inibidores deve-se as concentrações dos compostos inibidores presentes no hidrolisado serem muito baixas, pois na literatura a concentração para inibirem o crescimento de microrganismos pode variar, dependendo da biomassa e do pré-tratamento que foi empregado (Almeida et al, 2009). Para o furfural, a concentração encontrada foi de $0,4 \mathrm{~g} / \mathrm{L}$ para o Abeto (árvore conífera do gênero Abies da família Pinaceae) (Rudolf et al, 2004), enquanto que para a cana-de-açúcar e bagaço de cana-de-açucar 2,22 g/L (Neureiter et al, 2002). Para o HMF a menor concentração encontrada foi de $0,06 \mathrm{~g} / \mathrm{L}$ para a palha de milho (Öhgren et al, 2005) e a maior foi de 3,0 g/L para o abeto (Rudolf et al, 2005).
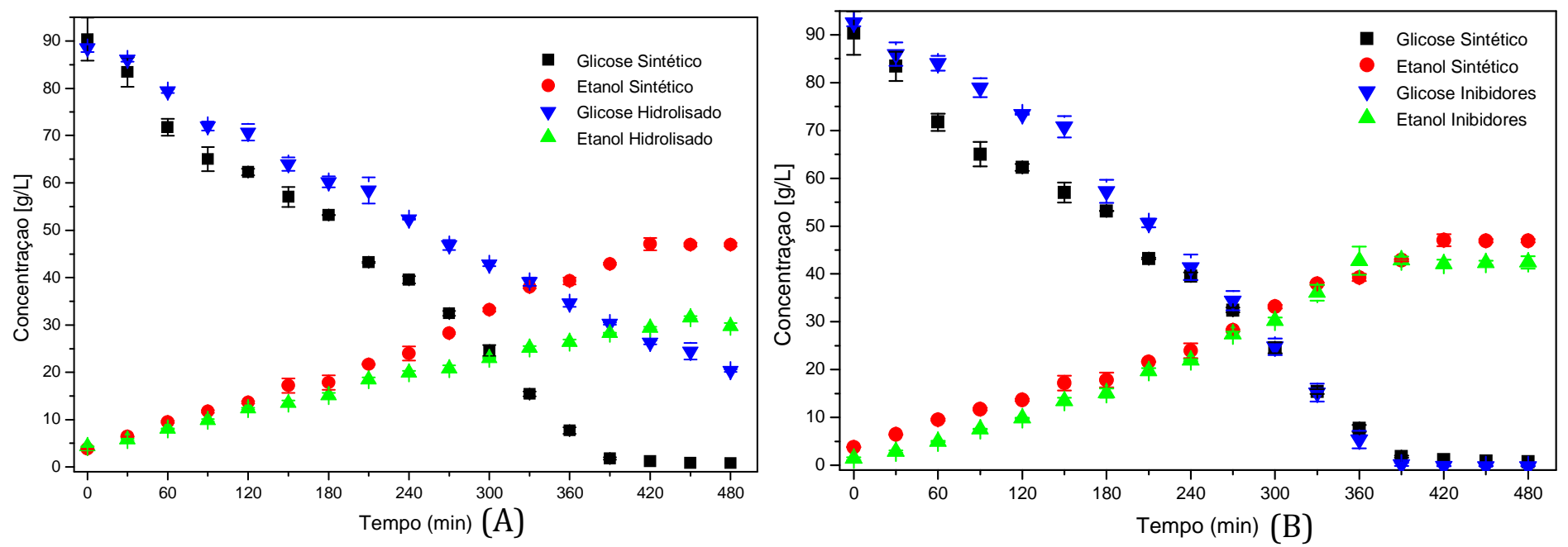

Figura 2 - Produção de etanol: (A) Comparação do meio sintético com o meio hidrolisado; (B) Comparação do meio sintético com o meio sintético com inibidores.

Os resultados apresentados na Figura 2 nos permitem os cálculos dos parâmetros cinéticos da fermentação, comprovando a diferença no comportamento da levedura nos meios analisados. Para a taxa especifica máxima de crescimento microbiano $\left(\mu_{\max }\right)$ encontraram-se os seguintes resultados no meio sintético, hidrolisado e sintético com inibidores, respectivamente: $1,7 \times 10^{-3} \mathrm{~g} / \mathrm{h}^{-}$ ${ }^{1}, 0,5 \times 10^{-3} \mathrm{~g} / \mathrm{h}^{-1}$ e $1,1 \times 10^{-3} \mathrm{~g} / \mathrm{h}^{-1}$. Já o fator de conversão de substrato em produto $\left(\mathrm{Y}_{\mathrm{P} / \mathrm{S}}\right)$ os resultados foram, respectivamente, $0,48 \mathrm{~g}_{\text {etanol }} / \mathrm{g}_{\text {glicose }}, 0,37 \mathrm{~g}$ etanol $/ \mathrm{g}_{\text {glicose }}$ e $0,44 \mathrm{~g}_{\text {etanol }} / \mathrm{g}_{\text {glicose }}$, e por último, a eficiência da fermentação (E) foi de $94 \%, 72 \%$ e $86 \%$.

Os resultados do meio sintético com a presença dos compostos furfural e HMF foram bem próximos aos resultados do meio sintético puro. Contudo, é notável que a levedura não tenha apresentado a sua melhor conversão como no meio sintético puro e isso pode ser atribuído ao 


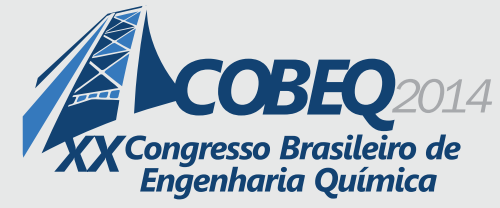

estresse que foi submetido pela presença destes compostos. E verificou-se que houve uma diminuição na via metabólica da levedura, o que acarretou uma queda na concentração final do produto no meio.

\section{CONCLUSÃO}

Os resultados mostram que a fermentação do hidrolisado de eucalipto apresenta eficiência muito aquém do desejado, contudo foi observado que o meio sintético com inibidores apresenta eficiência muito próxima ao meio sintético, demostrando que a presença dos inibidores, HMF e furfural, alteram o metabolismo da levedura, mas que não são os únicos responsáveis pela baixa eficiência na fermentação do hidrolisado de madeira.

\section{REFERÊNCIAS}

ALMEIDA, J. RM.; BERLILSSON, M.; GORWA-GRAUSLUND, M. F.; GORSICH, S.; LIDÉN, G. Metabolic effects of furaldehydes and impacts on biotechnological processes. Appl Microbiol Biotechnol., v. 82, p. 625-638, 2009.

CAETANO, A.C.G.; MADALENO, L.L. Controle de contaminantes bacterianos na fermentação alcoólica com a aplicação de biocidas naturais. Ciência \& Tecnologia, v. 2, p. 27-37, 2011.

GOMIDE, J. L.; NETO, H. F.; REGAZZI, A. J. Análise de critérios de qualidade da madeira de eucalipto para produção de celulose kraft. R. Árvore., v. 34, p. 339-344, 2010.

MOKFIENSKI, A.; GOMIDE, J. L. Colóquio Internacional sobre Celulose Kraft de Eucalipto. v. único, 5, 2003.

MOON, J.; LIU, Z.L. Engineered NADH-dependent GRE2 from Saccharomyces cerevisiae by directed enzyme evolution enhances HMF reduction using additional cofactor NADPH. Enz. and Microbial Technol., v. 50, p. 115-120, 2012.

NEUREITER, M.; DANNER, H.; THOMASSER, C.; SAIDI, B.; BRAUN, R. Dilute-acid hydrolysis of sugarcane bagasse at varying conditions. Appl Biochem Biotechnol., v. 98, p. 49-58, 2002.

ÖHGREN, K.; GALBE, M.; ZACCHI, G. Optimization of steam pretreatment of SO2impregnated corn for fuel ethanol production. Appl. Biochem. Biotechnol., v. 124, p. 1055-1067, 2005.

OLEA, E.H.; CARRILLO, E.P.; SALDÍVAR, S.O.S. Effects of different acid hydrolyses on the conversion of sweet sorghum bagasse into C5 and C6 sugars and yeast inhibitors using response surface methodology. Bioresour. Technol., v. 119, p. 216-223, 2012.

RUDOLF, A.; ALKASRAWI, M.; ZACCHI, G.; LIDÉN, G. A comparison betweem batch and fed-batch simultaneous saccharification and fermentation of steam pretreated spruce. Enz. Microb. Technol., v. 37, p. 195-204, 2005.

RUDOLF, A.; GALBE, M.; LIDÉN, G. Controlled fed-batch fermentations of dilute-acid 
hydrolysate in pilot development unit scale. Appl Biochem Biotechnol., v. 114, p. 601-617, 2004.

SUN, Y.; CHENG, J. Hydrolysis of lignocellulosic materials for ethanol production: a review. Bioresour. Technol., v. 83, p. 1-11, 2002.

YANASE, H.; MITSUGU, H.; SAKURAI, M.; KAWAKAMI, A.; MATSUMOTO, M.; HAGA, K.; KOJIMA, M.; OKAMOTO, K. Ethanol production from wood hydrolysate using genetically engineered Zymomonas mobilis. Appl. Microbiol. Biotechnol., v. 94, p. 1667-1678, 2012.

ZHAO, H.; JONES, C. L.; BAKER, G. A.; XIA, S.; OLUBAJO, O.; PERSON, V. N. Regenerating cellulose from ionic liquids for an accelerated enzymatic hydrolysis. J. Biotechnol., v. 139, p. 47-54, 2009. 